\title{
Removal Potential of Particulate Matter of 12 Woody Plant Species for Landscape Planting
}

\author{
Kei-Jung Kwon ${ }^{1}$, Odsuren Urrintuya ${ }^{2}$, Sang-Yong Kim ${ }^{3}$, Jong-Cheol Yang ${ }^{4,5}$, Jung-Won Sung ${ }^{6}$, and Bong-Ju Park ${ }^{7 *}$ \\ ${ }^{1}$ Researcher, Department of Horticultural Science, Chungbuk National University, Cheongju 28864, Korea \\ ${ }^{2}$ Masters student, Major in Horticulture, Graduate School, Chungbuk National University, Cheongju 28864, Korea \\ ${ }^{3}$ Director, Division of Plant Resources, Korea National Arboretum, Pocheon 11186, Korea \\ ${ }^{4}$ Researcher, Division of Plant Resources, Korea National Arboretum, Pocheon 11186, Korea \\ ${ }^{5}$ Senior manager, Forest Bioresources Conservarvation Division, Baekdudaegan National Arboretum, Bongwa 36209, Korea \\ ${ }^{6}$ Policy manager, Division of Garden \& Horticulture, Sejong National Arboretum, Sejong 30129, Korea \\ ${ }^{7}$ Professor, Department of Horticultural Science, Chungbuk National University, Cheongju 28864, Korea
}

\section{ABSTRACT}

Background and objective: Particulate matter (PM) is one of the serious environmental problems and threatens human health. Plants can clean the air by removing PM from the atmosphere. This study was carried out to investigate the PM removal efficiency of 12 species of woody plants.

Methods: Actinidia arguta, Dendropanax morbiferus, Fraxinus rhynchophylla, Parthenocissus tricuspidata, Pittosporum tobira, Rhaphiolepis indica, Rhapis, Salix integra, Salix koreensis, Schisandra chinensis, Viburnum odoratissimum var. awabuki, and Vitis coignetiae were used as plant material. Six $15 \mathrm{~cm}$ (D) pots were placed in an acrylic chamber of 800 (D) $\times 800(\mathrm{~W}) \times$ $1000(\mathrm{H}) \mathrm{mm}$. The LED panel was used as a light source. The reduction of PM10, PM2.5, and PM1 for 300 minutes after the injection of PM was automatically measured.

Results: The leaf area and the amount of PM in the chamber showed a negative correlation. 12 species of plants were compared by dividing the plants into 3 groups according to their characteristics: vines, trees, and shrubs and small trees. In the vine plant group, the averages of PM10, PM2.5, and PM1 were 7.917\%, 8.796\%, and 30.275\%, respectively. In the shrubs and small trees group, the average of PM10, PM2.5, and PM1 were $10.142 \%, 11.133 \%$, and 36.448\%, respectively. In the trees group, the average of PM10, PM2.5, and PM1 were $11.475 \%, 12.892 \%$, and $40.421 \%$, respectively. When the initial concentration was $100 \%$, PM10, PM2.5, and PM1 of Viburnum odoratissimum var. awabuki with the largest leaf area were $5.6 \%, 6.3 \%$, and $21.0 \%$ after 5 hours, respectively, the best results among 12 species of plants.

Conclusion: The vine plant group was more effective in removing PM than the other two groups. In the tree groups, the fact that the leaf development was relatively inactive at a plant height of $30 \mathrm{~cm}$ was considered to have an effect on the removal of particulate matter.

Keywords: air purification, PM1, PM2.5, PM10

\section{Introduction}

Contaminants in air are classified into particulate substances and gaseous substances, and dust, which is a particulate contaminant, is classified according to the particle size based on total suspended particles, PM10 which is 10 $\mu \mathrm{m}$ or less in diameter and PM2.5 which is $2.5 \mu \mathrm{m}$ or less in diameter. PM10 and PM2.5 can cause or worsen acute and chronic respiratory diseases, increase the risk of cardiovascular, cerebrovascular diseases and arrhythmia and

This study was carried out with the support of 'R\&D Program for Forest Science Technology (Project No. 2019155B10-2021-0101)' provided by Korea Forest Service(Korea Forestry Promotion Institute).

Received: September 18, 2020, Revised: October 14, 2020, Accepted: December 2, 2020

First author: Kei-Jung Kwon, kkj0427@hanmail.net, (ib) https://orcid.org/0000-0002-4652-0605

*Corresponding author: Bong-Ju Park, bjpak@chungbuk.ac.kr, (1) https://orcid.org/0000-0001-5511-4812 
lead to early death in children and elderly and vulnerable people (Popek et al., 2013; Shin, 2007). As such, a range of measures are needed to protect the national health from high PM10 and PM2.5 concentrations.

Plants can adhere, absorb and eliminate contaminants from the above ground part, and planting-based air purification by microorganisms is possible (Beckett et al., 1998). Speak et al. (2012) carried out an experiment to remove PM by four green roof speceies - creeping bentgrass (Agrostis stolonifera), red fescue (Festuca rubra), ribwort plantain (Plantago lanceolata) and sedum (Sedum album) - that were normally used for extensive rooftop greening in downtown Manchester, England and predicted that the total rooftop greening area would be 325 ha if the rooftop greening was applied to the downtown area, and that such area could remove approximately $2.3 \%$ of the total amount of PM10 released in the city. The total leaf area of trees by tree age and the amount of PM2.5 adhesion were calculated using the parameter estimated value of the biomass model and the relative outgrowth table by tree part targeting pine trees, nut pine and oak trees, which were the species that were planted the most frequently in the country. The PM2.5 reduction effects caused by trees and economic benefits from such reduction were analyzed and the total economic benefits in terms of reduced medical expenses for respiratory and cardiovascular diseases from the 1 ton reduction of PM2.5 emissions was almost 100,001,872 KRW (Shin and Lim, 2018).

The air purification effect of plants has been known since 1980, but for a long time plants were not actively used for such purpose due to a number of problems, including insignificant purification volume and the requirements of plant care. However, as the advantages of plants including eco-friendliness and sustainability have recently been emphasized, various studies have been carried out to prepare basic data related to the capacity of plants to remove indoor pollution sources such as indoor formaldehyde and carbon dioxide (Park et al., 2008a; Park et al., 2008b).

It is considered that the use of appropriate gardening plants as biological filters can improve air quality and enhance heath. Yan et al. (2016) experimented with PM adhesion ability targeting Rosa xanthina which was a shrub, Broussonetia papyrifera which was a broad-leaf tree and
Pinus bungeana which was a needle-leaf tree in Beijing, China, and reported that shrubs displayed the highest PM adhesion effect, the shape of PM adhered to the leaves included particles with gentle boundary surface (86.4 93.8\%) and spherical particles (23.4\%), and the amount of PM adhesion varied according to the shape of the PM. Sæbø et al. (2012) investigated the amount of PM accumulated in the leaves targeting 47 woody plant species that were common in Norway and Poland in Northern Europe, and obtained a result indicating that no correlation was shown between the PM accumulation and the surface roughness and size of a leaf. Chen et al. (2015) investigated PM accumulated in the leaves targeting 24 woody plant species collected in Wuhan, China, and obtained a result indicating that even the same plant species showed different PM accumulation effects between the control group with relatively good air quality and the polluted area. In other words, the plant species that showed high PM accumulation in a highly polluted area was different from the plant species in the control group that showed high PM accumulation. It was reported that the plant species that showed high PM accumulation also varied according to the size of the PM. Wang et al. (2015) carried out a study on the structure of leaves and PM accumulation in the leaf development process using three deciduous species (Ulmus pumila L., Salix babylonica L., Ginkgo biloba L.) and reported the result, which indicated that more PM accumulation was shown in the upper side of the leaf, and that leaves with a smaller elevated surface scale were more effective in terms of PM2.5 accumulation. Przybysz et al. (2014) carried out a study on the accumulation of particle material according to plant pollution level of evergreen species (Taxus baccata L., Pinus sylvestris L., and Hedera helix L.), rainfall and the passage of time and presented a result indicating that it was necessary to consider plant species and the dynamics of deposition and leaf washing by rain during the season when evaluating the total PM removal effect of vegetation. In a study on PM removal efficiency according to the morphological characteristics of plant leave types, such as needle, compound, small and large leaves, Son et al. (2019) asserted that PM adhesion occurred frequently in the wax layer, which meant that needle-leaf trees with high wax layer content displayed high 
PM10 removal amount. Cho (2019) pointed out the problem that domestic and overseas studies on plants for PM reduction have mainly focused on plants' absorption function rather than their adhesion function, and as a result tree species for PM reduction were selected very unsystematically and studies were carried out mostly based on indoor foliage plants such as air purification plants selected by NASA.

In preceding studies on the selection of an effective plant for reducing fine dust, the leaves of trees planted mainly on roadsides in parks were collected and the amount of fine dust was measured and compared (Sæbø et al., 2012; Wang et al., 2015; Perini et al., 2017). Depending on the meteorological environment, PM may float longer or spread in the air instantly, or may sink immediately due to rainfall, so there is a large variation in the amount of PM accumulated in leaves. Vegetation also varies by country, so a study on plants that are abundant and can be utilized in our country is necessary. According to the Convention on Biological Diversity (Bell, 1992), which asserts the need to recognize the sovereignty over native species and mandates the preservation and monitoring system of native species, there is a growing interest in native plants as well as the utilization of species in the southern part of our country due to environmental changes such as global warming.

Therefore, 12 woody plant species including Dendropanax morbiferus, Pittosporum tobira and Viburnum odoratissimum var. awabuki, which were tree species in the southern species, were exposed to PM, and the amount of PM by hour was analyzed in order to select appropriate gardening plants for fast air purification after the occurrence of higher concentrations of PM.

\section{Materials and Methods}

\section{Plant material}

Actinidia arguta, Dendropanax morbiferus, Fraxinus rhynchophylla, Parthenocissus tricuspidata, Pittosporum tobira, Rhaphiolepis indica, Rhapis, Salix integra 'Hakuro Nishiki', Salix koreensis, Schisandra chinensis, Viburnum odoratissimum var. awabuki and Vitis coignetiae received from the Korea National Arboretum were used as plant materials, and the size of the plants used in the experiment was unified to a tree height of $30 \mathrm{~cm}$, with the exception of Parthenocissus tricuspidata, a vine. In a study on the PM accumulation targeting 24 woody plant species, Chen et al. (2015) asserted that Parthenocissus tricuspidata was effective for PM2.5 and PM0.2 accumulation. Therefore, Actinidia arguta, Vitis coignetiae, Parthenocissus tricuspidata and Schisandra chinensis, belonging to the vine plant group distributed in Korea, China and Japan, were used in this experiment. Dendropanax morbiferus, Pittosporum tobira and Viburnum odoratissimum var. awabuki were selected, since these plant species grew on beaches and islands in the southern part of our country, showed strong pollution, disease and pest resistance and received high interest as gardening plants in preparation for climate change (Jin et al., 2019). The received plants were planted on nursery bed soil (Wonjo Mix, Nongkyung, Korea) using a plastic flowerpot $15 \mathrm{~cm}$ in diameter and grew for 6 weeks in the greenhouse, and were acclimated in a laboratory environment for 2 weeks for PM tretment.

\section{Experiment method and data analysis}

6 pots were placed in each acrylic chamber $(800 \times 800 \times$ $1000 \mathrm{~mm}, \mathrm{~L} \times \mathrm{W} \times \mathrm{H}$ ) that modeled indoor space. Specified positions were marked in the chamber so that the 6 pots and the measuring instrument were placed in the specified positions. The LED white light source panel was installed at the top outside the acrylic chamber for Photosynthesis in plants, and the quantity of light at the top of the plants was $55 \mu \mathrm{mol} \cdot \mathrm{m}^{-2} \cdot \mathrm{s}^{-1}$ PPFD. To minimize the effect of external light other than the artificial light source, the chamber was covered with a blackout curtain with a $90 \%$ shading rate. Indoor temperature was set to $25^{\circ} \mathrm{C}$ using an air conditioner, and a fan was installed at the top of the light source in order to reduce the effect of heat generated from the LED light source panel installed at the top of the chamber on the acrylic chamber. A mosquito repellent incense (F-killer, SC Johnson, Korea) was used as the PM pollution source. The mosquito repellent incense was previously used as the pollution source in a study on indoor air quality of the wall-typed botanical biofiltration system (Chen et al., 
2015). The PM generation chamber was installed separately. The mosquito repellent incense was cut to a fixed length, ignited and placed in the chamber, and then the chamber was sealed immediately and only smoke generated at this time was injected into the chamber where plants were placed in order to minimize the effect of heat and carbon dioxide reduction that occurred due to the combustion of the mosquito repellent incense. When plants were placed in the chamber, each position was marked to place all 6 pots and the measuring instrument in their designated position and minimize measurement errors related to changes in the position of plants and the measuring instrument. After the end of each experiment, the acrylic chamber was cleaned and properly ventilated in order to ensure that no residual PM remained. PM1, PM2.5 and PM10 were measured through the gravimetric measurement method $\left(\mu \mathrm{g} \cdot \mathrm{m}^{-3}\right)$ using the PM measuring instrument (Aerocet 531S, Met One Instruments, Inc., USA). After injecting PM, the status of PM was measured automatically for 300 minutes and the experiment was repeated 6 times for each plant species. The experiment period was approximately 5 months, from mid-July to mid-December. The leaf area of plants was measured using the leaf area meter (Li-3000A, LI-COR, USA) after the fine dust experiment was completed.

The SAS 9.3 software package (SAS Institute Inc., USA) was used for statistical analysis, and Duncan's multiple range test (DMRT) at a 5\% significance level was carried out to assess the difference between the treatment means.

\section{Results and Discussion}

The characteristics and total leaf area of each plant are as shown in Table 1. Viburnum odoratissimum var. awabuki, an evergreen broad-leaf tree, showed the largest total leaf area at $6690.5 \mathrm{~cm}^{2}$, followed by Actinidia arguta $\left(3619.4 \mathrm{~cm}^{2}\right)$ and Fraxinus rhynchophylla $\left(3308.8 \mathrm{~cm}^{2}\right)$, while Dendropanax morbiferus $\left(866.2 \mathrm{~cm}^{2}\right)$, Schisandra chinensis $\left(763.2 \mathrm{~cm}^{2}\right)$ and Rhapis $\left(700.0 \mathrm{~cm}^{2}\right)$ showed a relatively smaller total leaf area.

When the mosquito repellent incense was initially injected into the chamber based on $1027.7 \pm 27.2 \mu \mathrm{g}$ for the amount of PM10, the amount of PM2.5 was $916.7 \pm$ $29.9 \mu \mathrm{g}$ which was approximately $89 \%$ of the amount of PM10 and the amount of PM1 was $232.3 \pm 6.7 \mu \mathrm{g}$ which was approximately $23 \%$ of the amount of PM10 (Fig. 1). The ratio of PM2.5 and PM1 increased gradually over time. When the experiment was $50 \%(1 / 2)$ completed, the amount of PM10 was $282.8 \pm 28.2 \mu \mathrm{g}$ and the amount of PM2.5 was $272.8 \pm 29.1 \mu \mathrm{g}$, which was approximately $94 \%$ of the amount of PM10, and the amount of PM1 was $172.0 \pm 15.6 \mu \mathrm{g}$, which was approximately $61 \%$ of the amount of PM10. When 300 minutes had passed (at the end of the experiment), the amount of PM10 was $105.3 \pm$ $30.5 \mu \mathrm{g}$ and the amount of PM2.5 was $104.2 \pm 30.4 \mu \mathrm{g}$, which was approximately $94 \%$ of the amount of PM10; the amount of PM1 was $172.0 \pm 15.6 \mu \mathrm{g}$ which was approximately $61 \%$ of the amount of PM10. This is because

Table 1. Characteristics and total leaf area of plants used in the experiment

\begin{tabular}{cccc}
\hline Plant species & Family & Habit & Total leaf area $\left(\mathrm{cm}^{2}\right)$ \\
\hline Actinidia arguta & Actinidiaceae & Deciduous vine & 3619.4 \\
Dendropanax morbiferus & Araliaceae & Evergreen tree & 866.2 \\
Fraxinus rhynchophylla & Oleaceae & Deciduous tree & 3308.8 \\
Parthenocissus tricuspidata & Vitaceae & Deciduous vine & 2395.3 \\
Pittosporum tobira & Pittosporaceae & Evergreen shrub & 1106.4 \\
Rhaphiolepis indica & Rosaceae & Evergreen shrub & 1630.9 \\
Rhapis & Arecaceae & Evergreen tree & 700.0 \\
Salix integra & Salicaceae & Deciduous shrub & 2022.2 \\
Salix koreensis & Salicaceae & Deciduous trees & 2897.0 \\
Schisandra chinensis & Magnoliaceae & Deciduous vine & 763.2 \\
Viburnum odoratissimum var. awabuki & Asteraceae & Evergreen small tree & 6690.5 \\
\hline
\end{tabular}




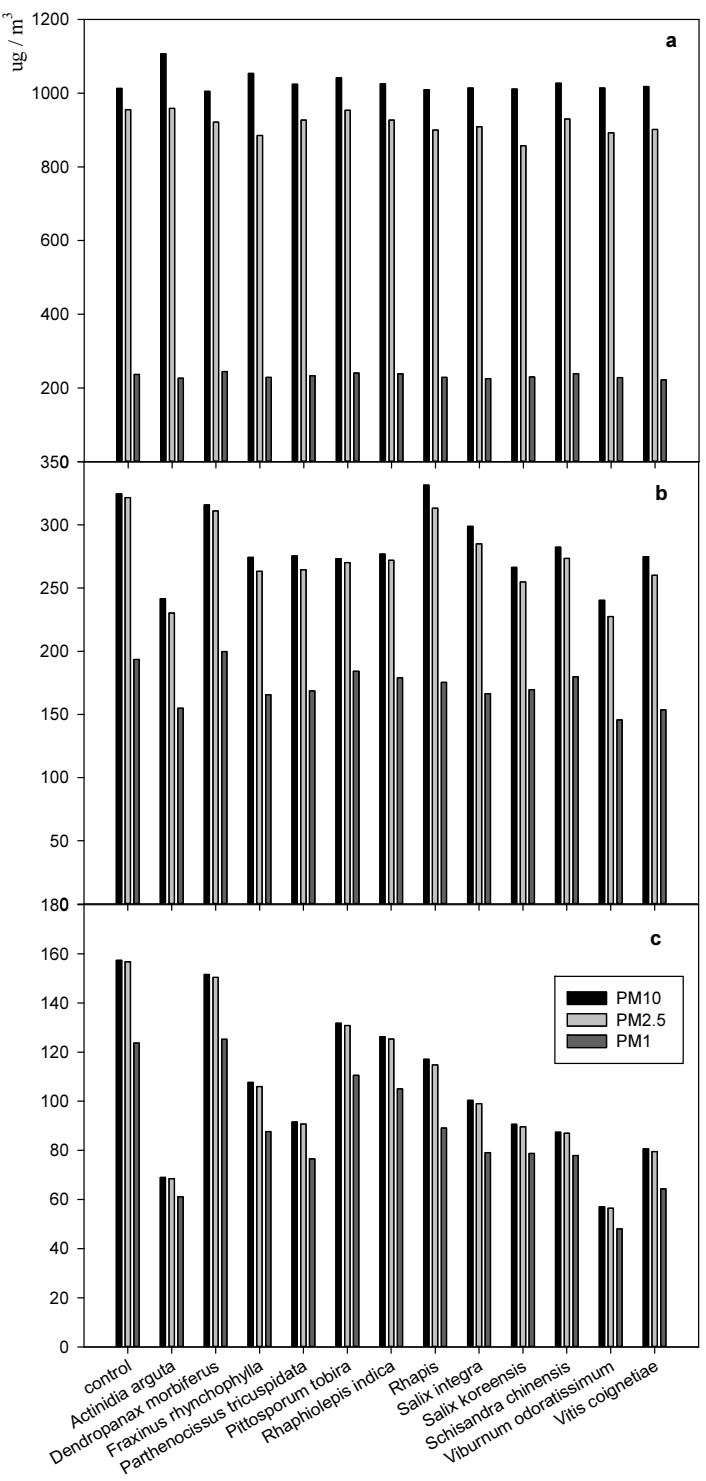

Fig. 1. The amounts of PM10, PM2.5, and PM1 in the chamber. $a=$ start ; $b=150$ minutes ; $c=300$ minutes.
PM1 settled more slowly and was segmented less, as its particle size was smaller in comparison to PM10, whose amount decreased rapidly and was segmented easily.

In a Pearson's correlation analysis between the total leaf area and the amount of PM in the chamber after $300 \mathrm{mi}-$ nutes, the correlation with PM10, PM2.5 and PM1 was $-0.740,-0.741$ and -0.738 respectively, showing a negative correlation (Fig. 2). As the total leaf area of a plant in the chamber was larger, the amount of residual PM was less, and this result indicated that the total leaf area of a plant affected the PM reduction in an area of the same volume, a finding that agrees with the result of a previous experiment on PM reduction according to the existence of a plant (Lohr and Pearson-Mims, 1996), and also indicates that PM was effectively removed when a plant was present in comparison to the control group with no plants.

While the experiment on PM reduction using a plant mainly measures the amount of PM extracted from collected plant leaves and compares the amount of PM adhesion per unit area, the comparison of trees for PM reduction effect by urban forests in the whole city calculates the amount of PM by estimating the total leaf area in consideration of tree age and crown (Liang et al., 2016), so the vine plant group with many leaves was effective in PM reduction in a sealed space such as a chamber. The result of comparing the amount of PM in the chamber after 300 minutes by converting the initial injection amount of PM10, PM2.5 and PM1 into a percentage is as shown in Table 2. Since the leaf development status of $30 \mathrm{~cm}$ high plants for the experiment varied depending on the plant properties, plants were classified into three groups including vines,

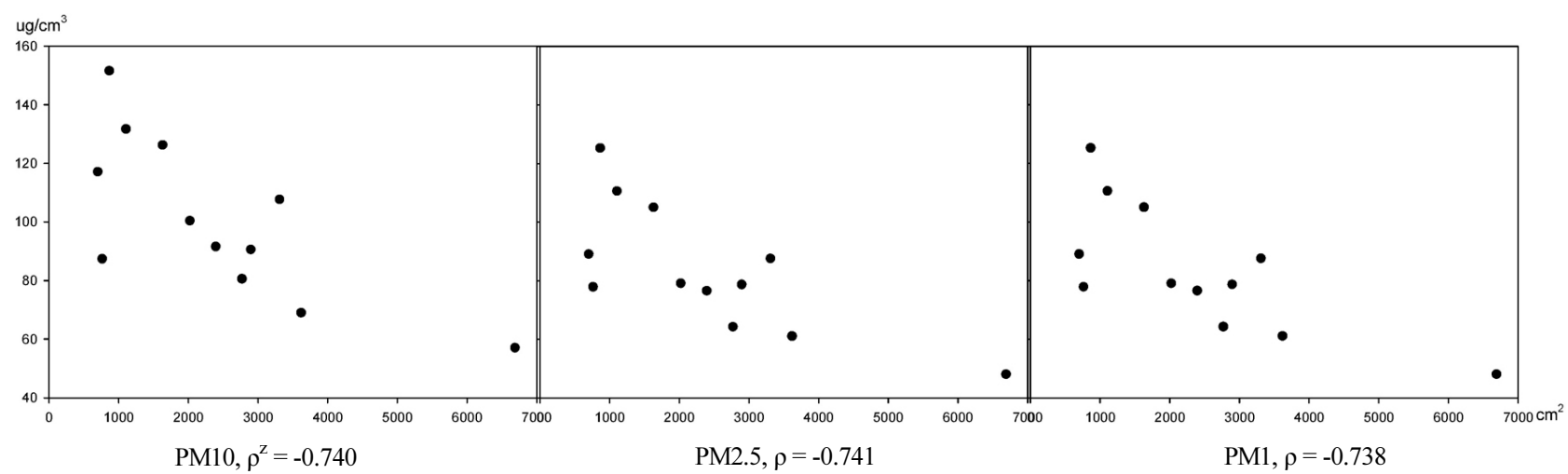

Fig. 2. Pearson correlation analysis for leaf area and PM. ${ }^{2}$ Means the Pearson correlation coefficient, $p<.05$. 
Table 2. PM10, PM2.5 and PM1 reduction for 12 species of woody plants according to time (\% )

\begin{tabular}{|c|c|c|c|c|}
\hline Habit & Plant species & PM10 & PM2.5 & PM1 \\
\hline \multirow{5}{*}{ Vine } & Actinidia arguta & $6.300 \mathrm{~b}^{\mathrm{z}}$ & $7.250 \mathrm{~b}$ & $26.967 \mathrm{~b}$ \\
\hline & Parthenocissus tricuspidata & $8.967 \mathrm{a}$ & $9.800 \mathrm{a}$ & $32.867 \mathrm{a}$ \\
\hline & Schisandra chinensis & $8.500 \mathrm{a}$ & $9.333 \mathrm{a}$ & $32.500 \mathrm{a}$ \\
\hline & Vitis coignetiae & $7.900 \mathrm{ab}$ & $8.800 \mathrm{ab}$ & $28.767 \mathrm{ab}$ \\
\hline & Significance & $*$ & $*$ & ns \\
\hline \multirow{5}{*}{ Tree } & Dendropanax morbiferus & $15.067 \mathrm{a}$ & $16.267 \mathrm{a}$ & $51.000 \mathrm{a}$ \\
\hline & Fraxinus rhynchophylla & $10.250 \mathrm{bc}$ & $12.033 \mathrm{bc}$ & $38.333 \mathrm{~b}$ \\
\hline & Rhapis & $11.617 \mathrm{~b}$ & $12.750 \mathrm{~b}$ & $38.883 \mathrm{~b}$ \\
\hline & $\begin{array}{l}\text { Salix } \\
\text { koreensis }\end{array}$ & $8.967 \mathrm{c}$ & $10.517 \mathrm{c}$ & $34.267 \mathrm{~b}$ \\
\hline & Significance & $* * *$ & $* * *$ & $* * *$ \\
\hline \multirow{5}{*}{$\begin{array}{c}\text { Shrub \& small } \\
\text { tree }\end{array}$} & Pittosporum tobira & $12.717 \mathrm{a}$ & $13.750 \mathrm{a}$ & $45.883 \mathrm{a}$ \\
\hline & Rhaphiolepis indica & $12.317 \mathrm{a}$ & $13.567 \mathrm{a}$ & $44.067 \mathrm{a}$ \\
\hline & Salix integra & $9.900 \mathrm{~b}$ & $10.883 \mathrm{~b}$ & $34.967 \mathrm{~b}$ \\
\hline & Viburnum odoratissimum var. awabuki & $5.633 \mathrm{c}$ & $6.333 \mathrm{c}$ & $21.033 \mathrm{c}$ \\
\hline & Significance & $* * *$ & $* * *$ & $* * *$ \\
\hline
\end{tabular}

${ }^{\mathrm{z}}$ Means separation within columns by Duncan's multiple range test, $p<.05$.

${ }^{\mathrm{ns}}$ Non-significant, ${ }^{*} p<.05,{ }^{* * *} p<.001$.

trees, and shrubs and small trees, and their PM reduction effects were compared. For the average amount of PM10, PM2.5 and PM1, the vine group showed $7.917 \%, 8.796 \%$ and $30.275 \%$ respectively, the shrubs and small trees group showed $10.142 \%, 11.133 \%$ and $36.448 \%$ respectively and the trees group showed $11.475 \%, 12.892 \%$ and $40.421 \%$ respectively. Based on the same height, vines that showed fast leaf development were more effective in the PM reduction. In a study carried out by Chen et al. (2015) on PM accumulation targeting 24 woody plant species, Parthenocissus tricuspidata was effective for PM2.5 and PM0.2 accumulation, showing the same result as this experiment, indicating that 4 vine species were effective in terms of their PM reduction. In addition, it is considered that Actinidia arguta, which showed the highest PM reduction effect among vines in this experiment, could play the same role with Hedera helix L, a vine frequently used for landscaping decoration, heat reduction and air purification in foreign studies on wall greening and rooftop greening (Sendo et al., 2010; Cuce, 2017; Przybysz et al., 2014).

Viburnum odoratissimum var. awabuki in the shrubs and small trees group showed the largest total leaf area and the smallest residual PM amount among target 12 plant species for the experiment. Perini et al. (2017) indicated that the amount of PM with particle sizes between $0.1 \mu \mathrm{m}$ and $20 \mu \mathrm{m}$ was the largest for Trachelospermum jasminoides, followed in order by Hedera helix, Cistus and Phlomis fruticose, when these 4 plant species were planted on the vertical greening system and the amount of PM accumulation was quantified. Trachelospermum jasminoides showed the largest amount of wax among these 4 plant species. In this experiment, Viburnum odoratissimum var. awabuki with hard and thick leaves and vines including Actinidia arguta, Vitis coignetiae, Schisandra chinensis and Parthenocissus tricuspidata also showed good results, indicating that these plant species were excellent for PM removal. Sgrigna et al. (2020) indexed 9 items including the micro-characteristics and morphological characteristics of a leaf including roughness, pore density, hair, leaf shape, time of leaf growth and leaf size, and determined the PM accumulation index by adding all these indexes. Sgrigna et al. (2020) also asserted that not one but all microscopic and macroscopic characteristics of a leaf were combined and interacted with each other, affecting the PM accumulation in the tree. In a study by Chen et al. (2015) on PM accumulation targeting 24 woody plant species, Pittosporum 
tobira leaves showed a small amount of PM0.2 accumulation, and the leaves used in this study also showed less of a PM reduction effect, and low PM reductione effect was caused by the total leaf area and other leaf characteristics of Pittosporum tobira. With regard to Fraxinus rhynchophylla and Salix koreensis, Fraxinus rhynnchophylla had a larger total leaf area than Salix koreensis, but Salix koreensis showed better PM10 and PM2.5 accumulation effects than Fraxinus rhynchophylla, so that there was a difference in the reduction effect according to the particle size of PM.

\section{Conclusion}

In this study, the amount of PM accumulation over time was investigated after contaminants were injected into the chamber in order to investigate the PM removal efficiency of 12 woody plant species. The 12 plant species used in this study were divided according to plant characteristics into 3 groups, which were vines, trees, and shrubs and small trees, and the comparison showed that the vine plant group was more effective in PM removal than the other two groups. There was a negative correlation between the total leaf area and the amount of PM in the chamber. Viburnum odoratissimum var. awabuki, which had the largest total leaf area, showed the smallest amount of PM remaining in the chamber after 5 hours for three PM types including PM10, PM2.5 and PM1 among the 12 tree species. It is considered that the relatively slower leaf development of the trees group than the other two groups affected its PM removal at the tree height of $30 \mathrm{~cm}$.

As such, it is considered that the PM reduction response of these 12 woody plant species can be used as basic data for selecting an appropriate tree species according to the size and floating characteristics of PM when planting trees as biological filters for yellow dust and contaminant leakage from factories, which have recently been frequently occurring. Various plant characteristics affect PM reduction, but in the simplest case, it is effective to select a tree species with a large total leaf area, and it is necessary to consider that plants should grow properly so that their leaves can be developed actively in order to achieve PM reduction effects using such plants.

\section{References}

Beckett, K.P., P.H. Freer-Smith and G. Taylor. 1998. Urban woodlands: their role in reducing the effects of particulate pollution. Environ. Pollut. 99(3):347-360. https://doi.org/10.1016/S0269-7491(98)00016-5

Bell, D.E. 1992. The 1992 convention on biological diversity: the continuing significance of US objections at the Earth Summit. George Washington J. Int. Law Econ. 26:479-537.

Chen, X., Z. Zhou, M. Teng, P. Wang, and L. Zhou. 2015. Accumulation of three different sizes of particulate matter on plant leaf surfaces: Effect on leaf traits. Arch. Biol. Sci. 67(4):1257-1267. https://doi.org/10.2298/ABS1503 $25102 \mathrm{C}$

Cho, D.G. 2019. Prioritization of species selection criteria for urban fine dust reduction planting. Korean J. Environ. Ecol. 33(4):472-480. https://doi.org/10.13047/KJEE.201 9.33.4.472

Cuce, E. 2017. Thermal regulation impact of green walls: An experimental and numerical investigation. Appl. Energy 194:247-254. https://doi.org/10.1016/j.apenergy. 2016.09.079

Jin, E.J., J.H. Yoon, E.J. Bae, and M.S. Choi. 2019. The comparative assessment of cold tolerance of broad-leaved evergreen trees by low temperature treatment. J. Korean Soc. For. Sci. 108(4):484-492. https://doi.org/10.14578/j kfs.2019.108.4.484

Liang, D., C. Ma, Y. Q. Wang, Y. J. Wang, and Z. Chen. 2016. Quantifying PM 2.5 capture capability of greening trees based on leaf factors analyzing. Environ. Sci. Pollut. Res. 23:21176-21186. https://doi.org/10.1007/s11356-0 16-7687-9

Lohr, V. I. and C. H. Pearson-Mims. 1996. Particulate matter accumulation on horizontal surfaces in interiors: Influence of foliage plants. Atmos. Environ. 30(14):2565-2568. https://doi.org/10.1016/1352-2310(95)00465-3

Park, J.S., J.H. Lee, and J.K. Suh. 2008a. Effect of several indoor plants on indoor air pollutants removal -Focused on removing formaldehyde-. J. Korean Soc. People Plants Environ. 11(1):13-25. 
Park, J.S., J.H. Lee, and J.K. Suh. 2008b. Effect of several indoor plants on indoor air pollutants removal -Focused on carbon dioxide-. J. Korean Soc. People Plants Environ. 11(1):59-72.

Perini, K., M. Ottelé, S. Giulini, A. Magliocco, and E. Roccotiello. 2017. Quantification of fine dust deposition on different plant species in a vertical greening system. Ecol. Eng. 100:268-276. https://doi.org/10.1016/j.ecoleng.201 6.12 .032

Popek, R., H. Gawrońka, M. Wrochna, S.W. Gawrońki, and A. Sabo. 2013. Particulate matter on foliage of 13 woody species:Deposition on surfaces and phytostabilisation in waxes 3-year study. Int. J. Phytoremediation 15(3):245-256. https://doi.org/10.1080/15226514.2012.694498

Przybysz, A., A. Sæbø, H.M. Hanslin, and S.W. Gawroński. 2014. Accumulation of particulate matter and trace elements on vegetation as affected by pollution level, rainfall and the passage of time. Sci. Total Environ. 481: 360-369. https://doi.org/10.1016/j.scitotenv.2014.02.072

Sæbø, A., R. Popek, B. Nawrot, H.M. Hanslin, H. Gawronska and S.W. Gawronski. 2012. Plant species differences in particulate matter accumulation on leaf surfaces. Sci. Total Environ. 427-428:347-354. https://doi.org/10.1016 /j.scitotenv.2012.03.084

Sendo, T., M. Kanechi, Y. Uno, and N. Inagaki. 2010. Evaluation of growth and green coverage of ten ornamental species for planting as urban rooftop greening. J. Jpn. Soc. Hortic. Sci. 79(1):69-76. https://doi.org/10.2 503/jjshs 1.79 .69

Sgrigna, G., C. Baldacchini, S. Dreveck, Z. Cheng, and C.
Calfapietra. 2020. Relationships between air particulate matter capture efficiency and leaf traits in twelve tree species from an Italian urban-industrial environment. Sci. Total Environ. 718:137310. https://doi.org/10.1016/j.scit otenv.2020.137310

Shin, D. C. 2007. Health effects of ambient particulate matters. J. Korean Med. Assoc. 50:175-182.

Shin, S.M, and S.S. Lim. 2018. Analysis of the effect of reducing ultra-fine dust by trees and economic benefits. Korea Environmental Economics Association. Summer Conference. 489-508.

Son, D.J., K.J. Kim, N.R. Jeong, H.G. Yun, S.W. Han, J.H. Kim, G.R. Do, S.H. Lee, and C.C. Shagol. 2019. The impact of the morphological characteristics of leaves on particulate matter removal efficiency of plants. J. People Plants Environ. 22(6):551-561. https://doi.org/10.11628/ksppe.2019.22.6.551

Speak, A.F., J.J. Rothwell, S.J. Lindley and C.L. Smith. 2012. Urban particulate pollution reduction by four species of green roof vegetation in a UK city. Atmos. Environ. 61:283-293. https://doi.org/10.1016/j.atmosenv. 2012.07.043

Wang, L., H. Gong, W. Liao, and Z. Wang. 2015. Accumulation of particles on the surface of leaves during leaf expansion. Sci. Total Environ. 532:420-434. https://doi.org/10.1016/j.scitotenv.2015.06.014

Yan, J., L. Lin, W. Zhou, L. Han, and K. Ma. 2016. Quantifying the characteristics of particulate matters captured by urban plants using an automatic approach. J. Environ. Sci. 39:259-267. https://doi.org/10.1016/j.jes.2015.11.014 